\title{
Pengaruh Katalis Genteng Tanah Liat dalam Proses Produksi Bahan Bakar Cair dari Limbah Ban Bekas dengan Proses Pirolisis
}

\author{
Andry Anggoro Arahim ${ }^{1}$, Widayat ${ }^{2}$, Hadiyanto ${ }^{3}$ \\ ${ }^{1}$ Magister Energi, Sekolah Pascasarjana, Universitas Diponegoro; \\ ${ }^{2}$ Departemen Teknik Kimia, Fakultas Teknik, Universitas Diponegoro; \\ Email : anggoroandry@gmail.com (A.A.A), widayat@lecturer.undip.ac.id (W), \\ hadiyanto@lecturer.undip.ac.id $(\mathrm{H})$;
}

\begin{abstract}
Abstrak : Penelitian ini bertujuan untuk melihat pengaruh katalis dari genteng tanah liat untuk memproduksi bahan bakar cair dari limbah ban bekas dengan proses pirolisis. Pirolisis menghasilkan produk yaitu cair (yield), arang (Char) dan gas. Alat pirolisis terdiri dari tabung reaktor, pipa stainless, pipa kaca, pipa kondensor dan kompor listrik. Katalis diletakkan pada pipa yang keluar dari reaktor sehingga katalis berperan dalam proses perubahan gas hasil pirolisis menjadi cair. Hasil XRF katalis genteng menunjukkan bahwa katalis genteng tanah liat mengandung silica alumina dimana dalam proses pirolisis silica alumina digunakan sebagai polimer, isomer dan pengkrekahan pada reaksi kimia hidrothermal. Hasil tanpa katalis menghasilkan yield lebih sedikit jika dibandingkan dengan penggunaan katalis. Yield di yeield dianalisis menggunakan Gas Chromatography-Mass spectrometry (GC-MS), hasil yield mengandung hidrokarbon dengan fraksi C5-C12 (bensin) sebesar $80,94 \%$.
\end{abstract}

Kata Kunci : Pirolisis, Katalis Genteng, GC-MS, Limbah Ban

\section{Pendahuluan}

Laju suatu reaksi kimia dapat dipengaruhi dengan menambahkan katalisator sebagai subtansi tanpa mempengaruhi hasil suatu reaksi (Syahputra, 2015). Katalisator hanya memberikan reaksi alternatif terhadap suatu reaksi kimia dan tidak mengalami perubahan pada ahir reaksi (Widjajanti, 2005). Katalisator tanah liat merupakan katalis yang ramah lingkungan, karena ternuat dari bahan alam yang mudah didapat. Katalis tanah liat digunakan karena tanah liat mempunyai sifat ecofriendly, ekonomis, dapat di daur ulang dan tidak korosif sehingga lebih efisien jika digunakan dalam reaksi organik (Theng, 1974; Krstic dkk., 2002; Aznárez dkk., 2015).

Teknologi pirolisis dapat digunakan untuk memperoleh sumber energi lain. Pirolisis adalah proses pembakaran dengan kondisi sedikit oksigen (Lailunnazar dkk., 2013). Genteng tanah liat di pecah menjadi ukuran $0.5-1 \mathrm{~cm}$ dan dilakukan uji katalis menggunakan X-ray fluorescence spectrometers and analyzers (XRF) digunanan untuk dapat mengetahui kandungan yang terdapat pada katalis genteng tanah liat. Pirolisis menghasilkan produk yaitu cair (yield), arang (Char) dan gas. Rangkaian alat pirolisis terdiri dari tabung reaktor, pipa stainless, pipa kaca, pipa kondensor dan 
Vol. 1, No. 2, pp $62-67$

doi: 10.14710/jebt.2020.9909

kompor listrik. Katalis diletakkan pada pipa yang keluar dari reaktor sehingga katalis berperan dalam proses perubahan gas hasil pirolisis menjadi cair. Hasil XRF katalis genteng menunjukkan bahwa katalis genteng tanah liat mengandung silica alumina dimana dalam proses pirolisis silika alumina dapat berperan sebagai polimerisasi, isomesisasi dan pengkrekahan pada reaksi kimia hydrothermal yang memungkinkan tanah liat dapat digunakan sebagai katalis. Hasil Yield akan di uji menggunakan alat GC-MS (Gas Chromatography-Mass Spectrometry) untuk megetahui kandungan yang terdapat pada yield.

\section{Metodologi}

Penelitian ini akan mengkaji pengaruh katalis dan tanpa katalis pada proses pirolisis ban bekas Bahan baku yang di gunakan dalan penelitian ini menggunakan ban dalam sepeda motor. Preparasi ban dilakukan dengan mencacah menjadi ukuran 0,5-1 cm dicuci dan dikeringkan. Preparasi katalis genteng tanah liat dilakukan dengan memecah genteng menjadi ukuran $0,5-1 \mathrm{~cm}$.

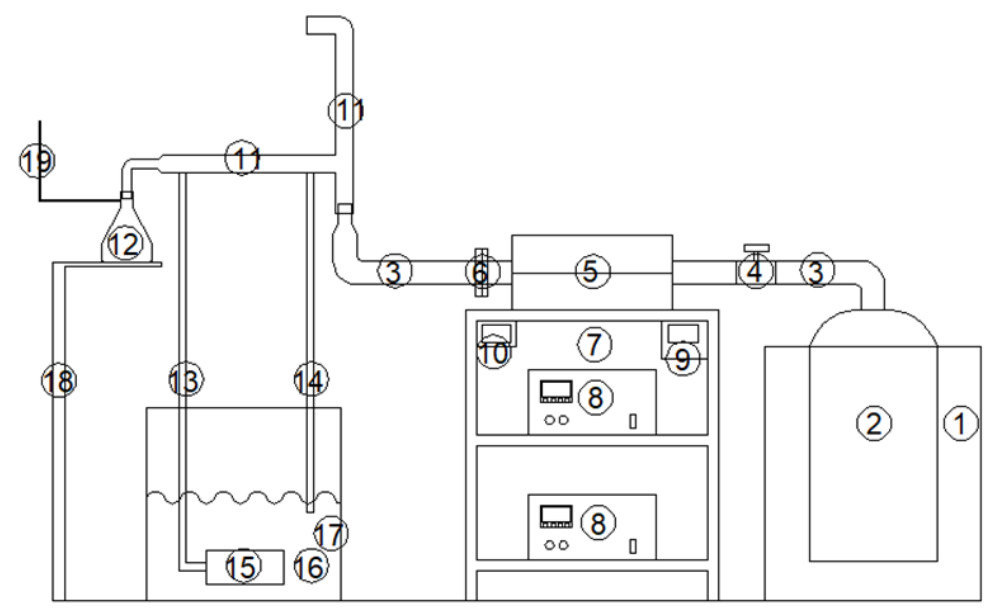

Keterangan :
1) Heater
11) Pipa destilasi kaca
2) Reaktor
12) Erlenmeyer
3) Pipa gas keluar
13) Pipa in kondensor
4) Ball Valve
14) Pipa out kondensor
5) Tempat katalis
15) Pompa air
6) Plandes
16) Air
7) Meja kontrol
17) Ember air
8) Kontrol
18) Holder
9) $\mathrm{kWh}$ meter
19) Flow gas
10) Indikator suhu reaktor

Gambar 1. Alat Pirolisis

Limbah ban dipotong dengan ukuran 0,5-1 cm ditimbang dengan berat 1000 gram dimasukkan kedalam reaktor. Katalis di masukkan kedalam pipa dengan memberi penyekat agar katalis tidak terbawa pada saat gas mengalir dalam pipa. Berat katalis di sesuaikan dengan tabel 1. Proses pirolisis dilakuan dengan memanaskan tabung reaktor menggunakan kompor listrik. Suhu dalam reaktor 
Vol. 1, No. 2, pp $62-67$

doi: 10.14710/jebt.2020.9909

diatur pada suhu $500^{\circ} \mathrm{C}$. Gas yang dihasilkan dialirkan melaui pipa yang berisi katalis dan gas akan terkondensasi agar menjadi yield. Cairan hasil pirolisis di tampung pada Erlenmeyer. Waktu pirolisis dihitung pada saat pemanasan. Hasil yield dilakukan uji GC-MS. Proses pirolisis di ulang berdasarkan tabel penelitian.

Tabel 1.

Pengambilan Data Pirolisis

\begin{tabular}{ccccc}
\hline Run & Waktu (jam) & Bahan & Temperatur Reaktor & Konsentrasi Katalis (\%) \\
\hline 1 & 2 & 1.000 & 500 & 0 \\
2 & 2 & 1.000 & 500 & 2,5 \\
3 & 2 & 1.000 & 500 & 3 \\
4 & 2 & 1.000 & 500 & 6 \\
5 & 2 & 1.000 & 500 & 5 \\
6 & 2 & 1.000 & 500 & 10 \\
\hline
\end{tabular}

\section{Hasil dan Diskusi}

\subsection{Karakteristik Katalis Genteng Tanah Liat}

Katalis pecahan genteng di uji menggunakan hasil Uji X-Ray Fluorosence (XRF) katalis mengandung beberapa unsur. Tabel 2 merupakan kandungan yang terdapat pada genteng tanah liat.

Tabel 2.

\begin{tabular}{cc}
\multicolumn{2}{c}{ Hasil Uji X-Ray Fluorosence } \\
\hline Komponen & Jumlah $(\%)$ \\
\hline Si & 21,8198 \\
$\mathrm{Al}$ & 17,8297 \\
$\mathrm{Fe}$ & 6,3436 \\
$\mathrm{~K}$ & 1,4679 \\
Balans & 52,5389 \\
\hline
\end{tabular}

Hasil XRF katalis genteng menunjukkan bahwa katalis genteng tanah liat mengandung silika alumina dimana dalam proses pirolisis silika alumina dapat berperan sebagai polimer, isomer dan pengkrekahan pada reaksi kimia hidrothermal.

\subsection{Pengaruh Katalis Terhadap Hasil Pirolisis}

Pirolisis ban kendaraan bermotor menghasilkan yield, gas dan sisa padatan. Hasil ditimbang dan dibandingkan antara percobaan satu dan percobaan lainnya.

Gambar 2 menunjukkan perbandingan yield menggunakan katalis dan tanpa katalis. Hasil yield tanpa katalis lebih sedikit menghasilkan yield jika dibandingkan dengan proses pirolisis menggunakan katalis, hal ini membuktikan penggunaan katalis membantu proses kondensasi gas menjadi yield.

Variabel katalis menghasilkan yield berbeda jumlahnya, hasil terbaik ketika proses pirolisis menggunakan katalis 3\% dengan hasil 38,7\%. Penambahan jumlah katalis lebih dari $3 \%$, hasil yield mengalami penurunan, hal ini di sebabkan karena produk gas yang melewati katalis mengalami depolimerisasi menjadi senyawa yang lebih sederhana yang menyebabkan fasa gas tidak dapat terkondensasi. 


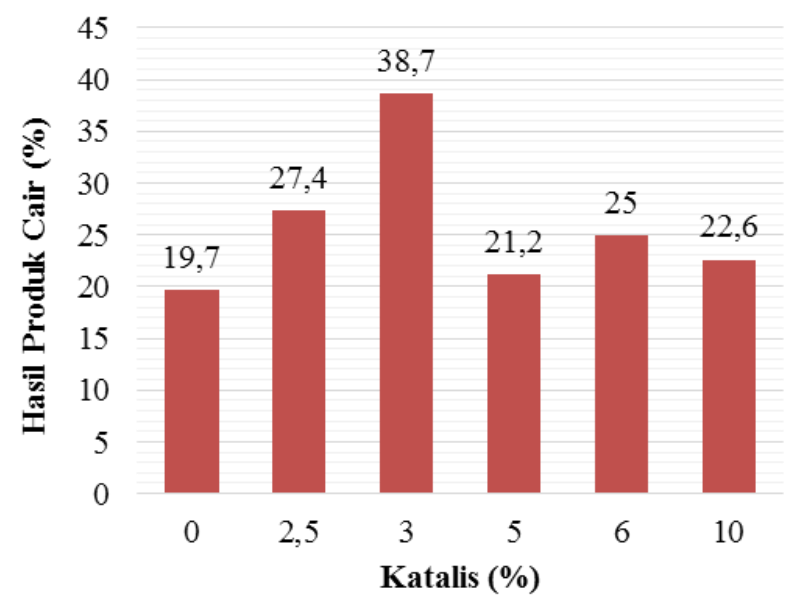

Gambar 2. Hasil Pirolisis Karet Ban dengan variabel katalis

\subsection{Uji Kualitatif GC-MS Yield}

Hasil uji GC-MS menghasilkan karakterisasi hidrokarbon yang terkadung dalam hasil yield.

Tabel 3.

Analisis GCMS yield

\begin{tabular}{cccl}
\hline No. & Formula & Jumlah (\%) & \multicolumn{1}{c}{ Nama } \\
\hline 1 & $\mathrm{C}_{4} \mathrm{H}_{6} \mathrm{BrCl}$ & 3,35 & Cyclobutane,1-bromo-3-chloro-(CAS) \\
2 & $\mathrm{C}_{6} \mathrm{H}_{8} \mathrm{~N}_{2}$ & 2,95 & Pyrazine,2,3-dimethyl-(CAS) \\
3 & $\mathrm{C}_{7} \mathrm{H}_{12}$ & 4,64 & 2,4-Hexadiene,2-methyl- \\
4 & $\mathrm{C}_{7} \mathrm{H}_{12}$ & 4,15 & Cyclohexene,4-methyl-(CAS) \\
5 & $\mathrm{C}_{7} \mathrm{H}_{9} \mathrm{~N}$ & 16,37 & 1-Cyclopentylacetonitrile \\
6 & $\mathrm{C}_{7} \mathrm{H}_{8}$ & 9,12 & 1,5-Hexadien-3-yne, 2-methyl- \\
7 & $\mathrm{C}_{7} \mathrm{H}_{8}$ & 4,81 & 1,6-Heptadiyne (CAS) \\
8 & $\mathrm{C}_{8} \mathrm{H}_{12}$ & 2,5 & 1,3-Cyclooctadiene(CAS) \\
9 & $\mathrm{C}_{9} \mathrm{H}_{12}$ & 3,6 & 3-Ethylidene-6-methylene-1-cyclohexene \\
10 & $\mathrm{C}_{9} \mathrm{H}_{12}$ & 3,9 & Cyclohexane,1,2,4-Tris(Methylene)- \\
11 & $\mathrm{C}_{10} \mathrm{H}_{14}$ & 7,69 & 2,6- Dimethyl-1,3,5,7- octatetraene, E,E \\
12 & $\mathrm{C}_{10} \mathrm{H}_{14}$ & 7,69 & 2,6- Dimethyl-1,3,5,7- octatetraene,E,E \\
13 & $\mathrm{C}_{10} \mathrm{H}_{16}$ & 12,27 & Cyclohexene,1-Methyl-4-(1-Methylethenyl) \\
14 & $\mathrm{C}_{10} \mathrm{H}_{12}$ & 2,5 & Benzene,1-Methyl-4-(1-Methylethenyl)-(CAS) \\
15 & $\mathrm{C}_{11} \mathrm{H}_{20} \mathrm{O}$ & 3,52 & (+)(IR)-2,2- Dimethyl-3-[methylidene] cyclohexane-1- \\
16 & $\mathrm{C}_{14} \mathrm{H}_{24}$ & 2,7 & Phenanthrene,tetradecahydro- \\
17 & $\mathrm{C}_{17} \mathrm{H}_{23} \mathrm{NO}_{3}$ & 3,3 & Cyclopropanecarboxamide,2,2-Dimethyl-3-(2-Methyl-2-Propenyl)- \\
& & & N-(4-Methylphenyl)- \\
18 & $\mathrm{C}_{18} \mathrm{H}_{23} \mathrm{NO}_{3}$ & 2,61 & 2-Oxo-1-Oxa-Spiro [4,5] Decane-4-Carboxylic Acid Phenethyl- \\
& & & Amide \\
19 & $\mathrm{C}_{22} \mathrm{H}_{32} \mathrm{O}_{3}$ & 3,28 & Cyclohexyl-(10-Phenyl-9,11-Trans- \\
& & & Dioxabicyclo[6.3.0]Undecanyl)Methanol \\
20 & $\mathrm{C}_{21} \mathrm{H}_{18} \mathrm{~N}_{2} \mathrm{O} \mathrm{O}_{5}$ & 3,83 & 2-[4-(BENZYLOXY)PHENOXY]-N-(4-NITROPHENYL) \\
& & & ACETAMIDE \\
\hline
\end{tabular}


Pada tabel 3 fraksi $C_{5}-C_{12}$ merupakan fraksi terbanyak dengan rata-rata produksi 80,94\% yang tergolong minyak bensin. Produksi terbesar kedua fraksi $\mathrm{C}_{13}-\mathrm{C}_{20}$ dengan rata-rata produksi $8,60 \%$ yang merupakan yang tergolong minyak diesel. Fraksi $>\mathrm{C}_{20}$ merupakan fraksi minyak berat sebanyak $7,11 \%$.

\section{Kesimpulan}

Katalis genteng tanah liat dapat digunakan sebagai katalis karena mengandung silica alumina. Penggunaan katalis genteng tanah liat mempengaruhi laju reaksi dalam proses kondensasi gas menjadi yield. Fraksi terbesar hasil pirolisis ban bekas adalah fraksi bensin sebesar $80.94 \%$ yang merupakan fraksi bensin.

\section{Daftar Pustaka}

Andry, A. A., Widayat, \& Hadiyanto. (2020). Liquid fuel production from motorized vehicle tires with pirolysis process. AIP Conference Proceedings, 6.

Anyela , R.-C., Muñoz-Camelo , Y., \& Singh, P. (2018). Decomposition of Used Tyre Rubber by Pyrolysis: Enhancement of the Physical Properties of the Liquid Fraction Using a Hydrogen Stream. Environments, 1-12.

Arita, S., Assalami, A., \& Naibaho, D. I. (2015). Proses Pembuatan Bahan Bakar Cair Dengan Memanfaatkan Limbah Ban Bekas Menggunakan Katalis Zeolit. Jurnal Teknik Kimia , 8-14.

Aznárez, A., Delaigle, R., Eloy, P., Gaigneaux, E. M., Korili, S. A., Gil, A. (2015) Catalysts based on pillared clays for the oxidation of chlorobenzene, Catalysis Today, 246, 15 - 27.

Damayanthi , R., \& Martini , R. (2009). Proses Pembuatan Bahan Bakar Cair Dengan Memanfaatkan Limbah Ban Bekas Menggunakan Katalis Zeolit Y Dan Zsm-5. Jurusan Teknik Kimia, Fakultas Teknik Universitas Diponegoro .

Diez, C., Martinez, O., Calvo, L. F., Cara, J., \& Moran, A. (2003). Pyrolysis of tyres. Influence of the final temperature of the process. Waste ManagementDepartment of Chemical Engineering, Institute of Natural Resources, University of Leo' n,, 463-469.

Galvagno, S., Casu, S., Casabianca, T., Calabrese, A., Cornacchia, G.2002. Pyrolisis process for the treadment of scrap tyres: Progres In Energy And Combustion Peraturan Menteri ESDM No. 28 tahun 2016 tentang Tarif Tenaga Listrik Yang Disediakan Oleh PT. Perusahaan Listrik Negara (Persero).

Handono, M. R. (2017). Laporan Penelitian Pembuatan Bahan Bakar Cair Dengan Memanfaatkan Limbah Ban Bekas Menggunakan Katalis Dari Limbah Bekas Perengkahan Minayak Bumi Pt. Pertamina Ru Iii Dengan Metode Pirolisis. Palembang: Program Studi Teknik Kimia Fakultas Teknik Universitas Muhammadiyah Palembang .

Krstic, L J., Sukdolak, S., Solujic, S. (2002) An efficient synthesis of warfarin acetals on montmorillonite clay K-10 with microwaves, Journal of Serbian Chemical Society, 67 (5), 325 - 329.

Lailunnazar, L., Wijayanti, W., Sasongko, M.N. (2013) Pengaruh temperatur pirolisis terhadap kualitas tar hasil pirolisis serbuk kayu Mahoni, Skripsi, Jurusan Teknik Mesin, Universitas Brawijaya.

Putra, E. A., Rahman, M., \& Aminy, A. Y. (2016). Produksi Bahan Bakar Ramah Lingkungan Melalui Proses Pirolisis Limbah Ban. Jurnal JPE Vol. 20, No. 2, 26-31.

Saputra, I. A., \& Arijanto. (2017). Pengujian Alat Konversi Ban Bekas Menjadi Bahan Bakar . Jurnal Teknik Mesin S-1, Vol. 5, No. 2, 82-90. 
Vol. 1, No. 2, pp $62-67$

doi: 10.14710/jebt.2020.9909

Stelmachowski , M., \& Słowiński , K. (2009). Conversion of waste rubber as an alternative rout to renewable fuel production. Energy and Sustainability II , 489-498.

Surdia, T., dan S. Saito 2005, Pengetahuan Bahan Teknik. Pradanya Paramita, Jakarta.

Syahputra, R. J., Utami, T., Nugrahaningtyas, K. D., Ridasepri, A. F., \& Astuti, W. (2015). Pemanfaatan Limbah Pecahan Genteng sebagai Katalis dalam Reaksi Pirolisis Plastik Polipropilena Menjadi Bahan Bakar Alternatif. Jurusan Kimia, Fakultas Matematika dan Ilmu pengetahuan Alam, Universitas Sebelas Maret, 127-134.

Theng, B.K.G. (1974) The chemistry of clayorganic reactions, Hilger, London.

Widjajanti LFX, E. (2005). Pengaruh Katalisator Terhadap Laju Reaksi. Yogyakarta: Pelatihan Tentang Keterampilan Menyiapkan Praktikum Kimia Bagi Laboran Laboratorium Kimia Smama Diy. 